\title{
Effect of Postoperative Administration of Saireito for Bilateral Chronic Subdural Hematomas
}

\author{
Satoshi Utsuki, Hidehiro Oka, Chihiro Kijima, Madoka Inukai, Katsutoshi Abe, Kimitoshi Sato, \\ Sachio Suzuki, Kiyotaka Fujii
}

Department of Neurosurgery, School of Medicine, Kitasato University, Sagamihara, Japan.

Email: utsuki@med.kitasato-u.ac.jp

Received April 1 ${ }^{\text {st }}, 2011$; revised April 29 ${ }^{\text {th }}, 2011$; accepted May $26^{\text {th }}, 2011$.

\begin{abstract}
The aim of this retrospective study was to investigate the efficacy of saireito for bilateral chronic subdural hematomas (B-CSDH). Between April 2006 and March 2010, a total of 18 patients undergoing unilateral burr hole drainage for $B-C S D H$ took part in a controlled clinical study. Postoperative status of the nonsurgical side was subsequently evaluated, with $(n=10)$ and without $(n=8)$ saireito administration. Two in the saireito-treated group patients and four in the control group patients ultimately required contralateral surgical intervention. The remainder, including eight saireito-treated hematomas, resolved without further surgery, generally within eight weeks of the surgical side procedure. However, two of the four resolving control lesions took longer to regress. The hydragogue and anti-inflammatory/steroid-evoking properties ascribed to saireito may facilitate hematoma resolution. After unilateral surgery for $B$-CSDH, saireito administration may prevent symptomatic deterioration of a contralateral low-density CSDH, preempting subsequent surgery.
\end{abstract}

Keywords: Bilateral Chronic Subdural Hematomas, Contralateral Hematoma, Medical Treatment, Saireito, Steroid-Like Effect

\section{Introduction}

Patients with chronic subdural hematoma (CSDH) often present with mental dullness, hemiparesis, and headache, indicating that surgical intervention is needed. Should a patient refuse surgery or have few, if any, symptoms, therapeutic success has been reported with the Japanese traditional medicine, goreisan $[1,2]$, as an alternative to steroid [3-5]. Similarly, saireito is an herbal remedy incorporating the ingredients and activity of goreisan, but with added steroid-like effect [6,7]. Since saireito has therapeutic potential for treatment of CSDH, this study was conducted to evaluate its administration after unilateral surgical drainage in patients with bilateral CSDH (B-CSDH). The contralateral lesions were assessed postoperatively, with and without saireito treatment.

\section{Materials and Methods}

Between April 2008 and March 2010, 10 patients with $\mathrm{B}-\mathrm{CSDH}$, undergoing unilateral surgical drainage, were evaluated for postoperative changes in the contralateral lesions with administration of saireito (saireito group). All B-CSDH cases of this period were enrolled in con- trolled clinical study. The medication was given as a single $3.0 \mathrm{gm}$ dose before mealtime with cold water, from the day following surgery until the hematoma resolved. Dimensions of clot were measured from the inner skull to the brain on axial CT views. Contralateral lesions were assessed at hematoma maximum dimension and hematoma density by $\mathrm{CT}$, and change in CT density, spontaneous resolution and number of required surgeries were recorded.

Between April 2006 and March 2008, eight control patients treated with unilateral surgery for B-CSDH were studied for comparison retrospectively as control group. None received postoperative saireito.

CT scans of the head were performed on all patients at four-week intervals or when there were signs of deterioration due to hematoma, for example declining mental faculties, hemiparesis and headache.

Significant differences were analyzed using Stat View 5.0 software. The $p$ value using a $t$-test for age, the maximum dimension of contralateral hematoma and interval until surgery for contralateral hematoma was calculated, and a chi-square test (Fisher's exact test) was 
used to determine the significance in the other factors.

\section{Results}

Mean age of patients given saireito was $70 \pm 9.3$ years (range, 61 - 86 years). Seven were males and three were females. Mean age for the control group was $66 \pm 13.1$ years (range, 45 - 85 years), with four males and four females. The mean maximum dimension of contralateral CSDH was $14.0 \pm 5.3 \mathrm{~mm}$ (range $6.0-21.0 \mathrm{~mm}$ ) in saireito recipients and $11.0 \pm 4.5 \mathrm{~mm}$ (range $6.0-16.0$ $\mathrm{mm}$ ) in the control group. Contralateral lesions were initially mixed or isodense on CT scan in seven patients of the saireito treatment group and in three members of the control group, but showed a low density in three saireito-treated patients and five control patients. There were no significant differences between groups relative to these features (Table 1). Overall, two patients on saireito and four control subjects needed surgical drainage of enlarging contralateral hematomas. The period before the onset of symptoms was one to two weeks for those receiving saireito, but up to eight weeks (mean, five weeks) for the control patients. Contralateral hematomas resolved without further surgery in eight saireito-treated patients and in four controls. While all eight hematomas of saireito group resolved in less than eight weeks (Figure 1), two of the four resolving lesions in the control group took longer (12 - 16 weeks) to regress.

Of the contralateral hematomas eventually needing surgical drainage, three were mixed or isodense (two in saireito group, Figure 2), and three were low-density at presentation. Three hematomas requiring surgical intervention at later time points (Figure 3) were all in control patients, and all were low-density lesions.

Maximum dimension of contralateral hematomas at presentation did not differ by patient group (Figure 4).

Table 1. Summary of patient characteristics.

\begin{tabular}{lll}
\hline & Saireito & Control \\
\hline & group $(n=10)$ & group $(n=8)$ \\
Age (mean) & $61-86(70)$ & $45-85(66)$ \\
Male:Femal & $7: 3$ & $4: 4$ \\
Use of the anticoagulant & $2 / 10$ & $1 / 8$ \\
Contralateral hematoma & & \\
Maximum dimension (mm) & $6-21$ & $6-16$ \\
Mean (mm) & 14 & 11 \\
$\begin{array}{l}\text { Density of hematoma } \\
\text { Mixed or iso }\end{array}$ & 7 & 3 \\
Low & 3 & 5 \\
$\begin{array}{l}\text { Surgery required } \\
\text { Interval until surgery }\end{array}$ & $2 / 10$ & $4 / 8$ \\
Regression without surgery & $8 / 10$ & $1-8 \mathrm{w}$, mean $5 \mathrm{w}$ \\
Regression time & & $4 / 8$ \\
$<8$ weeks & 8 & 2 \\
$>8$ weeks $<$ & 0 & 2 \\
\hline
\end{tabular}

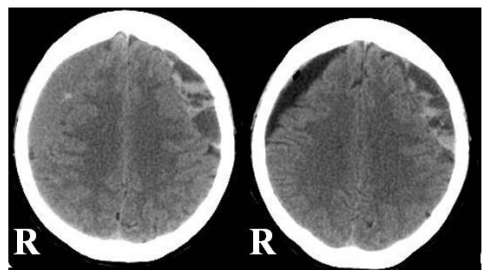

(a)

(b)

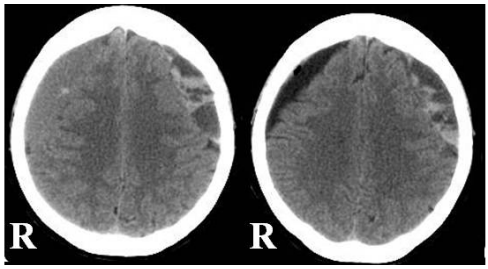

(c)

(d)

Figure 1. Cranial CT of 76-year-old female hospitalized with left hemiplegia (a). Evacuated mixed-density B-CSDH on right; left lesion asymptomatic and unchanged in postoperative CT (b). Single-dose saireito $(3.0 \mathrm{gm})$ given before meal with cold water, initiated on day following surgery. Four weeks after right-sided CSDH surgery, mixed-density left CSDH appears low-density and diminished in size (c). Both hematomas resolved eight weeks postoperatively (d).

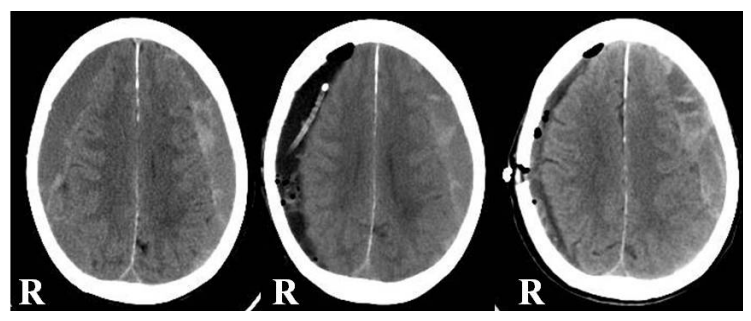

(a)

(b)

(c)

Figure 2. Cranial CT of 83-year-old female hospitalized with left hemiplegia (a). Mixed density B-CSDH with surgery on right; left asymptomatic and unchanged in postoperative CT (b). Single-dose saireito $(3.0 \mathrm{gm})$ given before meal with cold water, initiated on day following surgery. Right hemiplegia one week later, cranial CT with expanded CSDH on left (c).

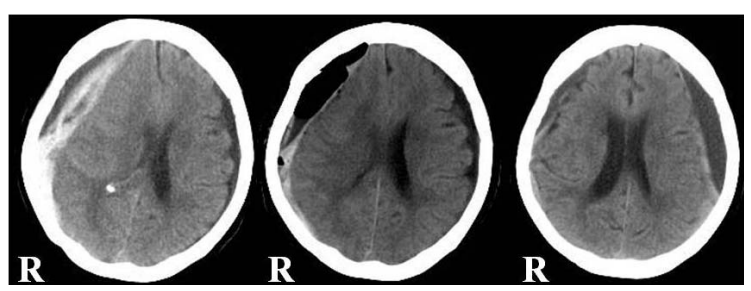

(a)

(b)

(c)

Figure 3. Cranial CT of 71-year-old female hospitalized with left hemiplegia (a). Right-sided mixed (slightly low) density CSDH with the midline shift to left; surgery performed on right. Improved midline shift on postoperative CT and left CSDH unchanged (b). Right hemiplegia eight weeks postoperatively; cranial CT with expanded CSDH on left (c). No saireito given. 
Maximun dimension contralateral hematoma $(\mathrm{mm})$

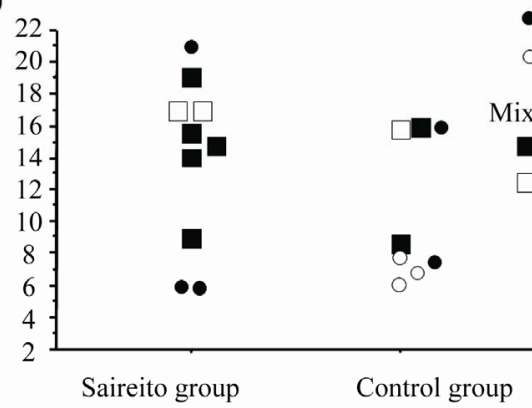

Figure 4. Contralateral hematoma: Maximum size and status comparison in saireito-treated and control groups. In mixed or isodense hematomas $>16.0 \mathrm{~mm}$, surgical treatment was uniformly needed. However, only three patients in the control group required surgery for low-density hematomas $<8.0 \mathrm{~mm}$.

More sizeable lesions ( $\geq 16.0 \mathrm{~mm}$ ) subjected to surgery were mixed or isodense. In contrast, small lesions $(\leq 8.0$ $\mathrm{mm}$ ) subjected to surgery were low-density, and all were confined to the control group.

In the three instances of mixed or isodense presentation, the interval from initial surgical side to contralateral surgery was less than two weeks. However, when hematoma density was low (three cases), the time for the onset of new neurologic symptoms (four to eight weeks) was longer (Figure 5).

\section{Discussion}

CSDH may be asymptomatic and may dissipate sponta-

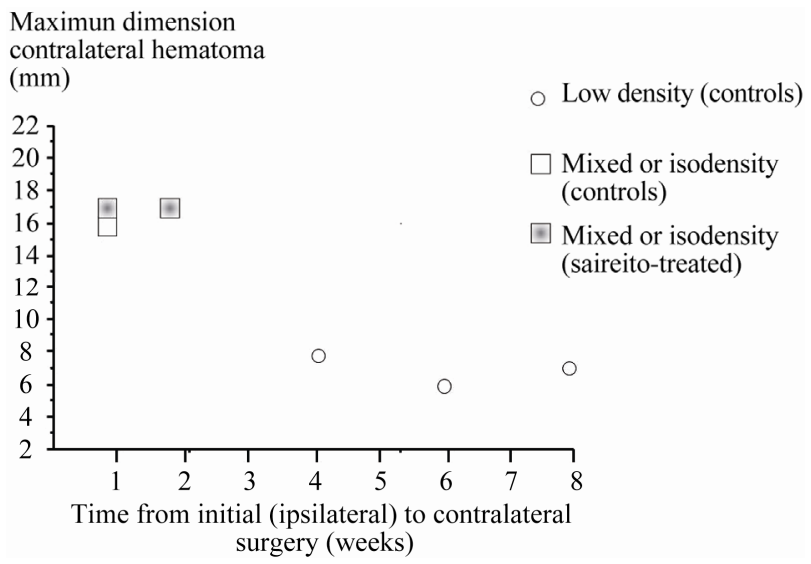

Figure 5. Distribution of contralateral hematoma density by maximum size and time between surgeries. In the saireito group, two patients required additional surgery within two weeks of initial intervention due to symptomatic enlargement of contralateral hematomas. In contrast, three patients in the control group experienced contralateral hematoma enlargement, with symptoms, at four to eight weeks postoperatively. These three lesions were of low density. neously, or symptoms may develop with a gradually enlarging $\mathrm{CSDH}$ [8]. Even with $\mathrm{B}-\mathrm{CSDH}$, symptoms are often attributable to a unilateral hematoma [9]. Although surgery is standard therapy for symptomatic CSDH, it is difficult to judge by images at a single point in time whether or not a silent contralateral hematoma will become symptomatic or regress spontaneously.

$\mathrm{CSDH}$ typically evolves from subdural hygroma or acute subdural hematoma (ASDH). Repeated microhemorrhages occur in the subdural space [8], provoked by local inflammation [10]. Any $\mathrm{CSDH}$ that enlarges with rebleeding, thus exceeding the capacity for absorption, may become symptomatic.

High or isodense CSDH on CT equates with proportionately higher red blood cell, hemoglobin, and protein concentrations, compared with those of low-density lesions [11]. Also, the time required for an acute hematoma to become chronic is often shorter than if subdural effusion or hygroma is involved $[12,13]$. In this study, mixed or isodense hematomas requiring contralateral surgery were $16.0 \mathrm{~mm}$ or larger at presentation, and the time prior to symptoms was relatively short $(1-2$ weeks). Understandably, they were unresponsive to saireito, just as with ASDH. In contrast, low-density hematomas where contralateral surgery was needed were typically $8.0 \mathrm{~mm}$ or smaller at presentation and remained asymptomatic longer (4 - 8 weeks). While contralateral lesions of some saireito-treated patients were small and showed a low density, none were symptomatic, and all eventually resolved without further surgery. Conversion of a contralateral subdural effusion or hygroma to $\mathrm{CSDH}$ is therefore seemingly prevented by saireito, suggesting that small, low-density $\mathrm{CSDH}$ is an indication for treatment.

In instances where asymptomatic hematomas regressed, the time required for resolution was also shorter with saireito, compared with that in controls. Use of goreisan1, [2] and steroid [3-7] in tandem for CSDH may reduce capsular inflammation, in addition to augmenting (via goreisan) resorption of clot. Saireito is actually a combination of goreisan and shosaikoto, another herbal anti-inflammatory; and it is believed that endogenous steroid production is boosted by saireito through enhanced expression of subthalamic corticotropin releasing factor [6,7]. Mechanistically, it is likely that saireito controls local inflammation to reduce continued CSDH bleeding and that absorption of accumulated blood is facilitated through its fluidic effects [14].

\section{Conclusions}

The therapeutic efficacy of sairei-to with CSDH reflects its hydragogue properties and its capacity to raise endogenous steroid levels. After unilateral surgery for 
B-CSDH, saireito administration may prevent symptomatic deterioration of a contralateral low-density $\mathrm{CSDH}$, preempting subsequent surgery.

\section{REFERENCES}

[1] M. Miyagami and Y. Kagawa, "Effectiveness of Kampo Medicine Gorei-San for Chronic Subdural Hematoma," No Shinkei Geka, Vol. 37, No. 8, 2009, pp. 765-770. (Japanese, with English abstract)

[2] M. Muramatsu, T. Yoshikawa and K. Hanabusa, "Effectiveness of Kampo Medicine Gorei-San-Ryo for Chronic Subdural Hematoma in very Elderly Patients," No Shinkei Geka, Vol. 33, No. 10, 2005, pp. 965-969. (Japanese, with English abstract)

[3] T. F. Sun, R. Boet and W. S. Poon, "Non-surgical Primary Treatment of Chronic Subdural Haematoma: Preliminary Results of Using Dexamethasone," British Journal of Neurosurgery, Vol. 19, No. 4, 2005, pp. 327333. doi:10.1080/02688690500305332

[4] J. L. Voelker, "Nonoperative Treatment of Chronic Subdural Hematoma," Neurosurgery Clinics of North America, Vol. 11, No. 3, 2000, pp. 507-513.

[5] S. Zarkou, M. I. Aguilar, N. P. Patel, K. E. Wellik, D. M. Wingerchuk and B. M. Demaerschalk, "The Role of Corticosteroids in the Management of Chronic Subdural Hematomas: A Critically Appraised Topic," Neurologist, Vol. 15, No. 5, 2009, pp. 299-302. doi:10.1097/NRL.0b013e3181b65558

[6] I. Iwai, T. Suda, F. Tozawa, Y. Nakano, Y. Sato, N. Ohmori, T. Sumitomo, M. Yamada and H. Demura, "Stimulatory Effect of Saireito on Proopiomelanocortin Gene Expression in the Rat Anterior Pituitary Gland," Neuroscience Letters, Vol. 157, No. 1, 1993, pp. 37-40. doi:10.1016/0304-3940(93)90637-Z

[7] Y. Nakano, T. Suda, F. Tozawa, I. Dobashi, Y. Sato, N. Ohmori, T. Sumitomo and H. Demura, "Saireito (A Chinese Herbal Drug)-Stimulated Secretion and Synthesis of Pituitary ACTH Are Mediated by Hypothalamic Cortico-
tropin-Releasing Factor," Neuroscience Letters, Vol. 160, No. 1, 1993, pp. 93-95. doi:10.1016/0304-3940(93)90921-7

[8] K. S. Lee, "Natural History of Chronic Subdural Haematoma," Brain Injury, Vol. 18, No. 4, 2004, pp. 351-358. doi:10.1080/02699050310001645801

[9] T. H. Tsai, A. S. Lieu, S. L. Hwang, T. Y. Huang and Y. F. Hwang, "A Comparative Study of the Patients with Bilateral or Unilateral Chronic Subdural Hematoma: Precipitating Factors and Postoperative Outcomes," Journal of Trauma. Vol. 68, No. 3, 2010, pp. 571-575. doi:10.1097/TA.0b013e3181a5f31c

[10] H. J. Hong, Y. J. Kim, H. J. Yi, Y. Ko, S. J. Oh and J. M. Kim, "Role of Angiogenic Growth Factors and Inflammatory Cytokine on Recurrence of Chronic Subdural Hematoma," Surgical Neurology, Vol. 71, No. 2, 2009, pp. 161-166. doi:10.1016/j.surneu.2008.01.023

[11] H. Fujisawa, S. Nomura, E. Tsuchida and H. Ito, "Serum Protein Exudation in Chronic Subdural Haematomas: A Mechanism for Haematoma Enlargement?" Acta Neurochirungica Supplements (Wien), Vol. 140, No. 2, 1998, pp. 161-166. doi:10.1007/s007010050077

[12] C. K. Park, K. H. Choi, M. C. Kim, J. K. Kang and C. R. Choi, "Spontaneous Evolution of Posttraumatic Subdural Hygroma into Chronic Subdural Haematoma," Acta Neurochirungica Supplements (Wien), Vol. 127, No. 1-2, 1994, pp. 41-47. doi:10.1007/BF01808545

[13] S. H. Park, S. H. Lee, J. Park, J. H. Hwang, S. K. Hwang and I. S. Hamm, "Chronic Subdural Hematoma Preceded by Traumatic Subdural Hygroma," Journal of Clinical Neuroscience, Vol. 15, No. 8, 2008, pp. 868-872. doi:10.1016/i.jocn.2007.08.003

[14] T. Ono, N. Liu, T. Makino, F. Nogaki, E. Muso, G. Honda and T. Kita, "Suppressive Mechanisms of Sairei-to on Mesangial Matrix Expansion in Rat Mesangioproliferative Glomerulonephritis," Nephron Experimental Nephrology, Vol. 100, No. 3, 2005, pp. e132-e142. doi: $10.1159 / 000085059$ 